\title{
Time to Patients' Access to New Medicines in Greece: Evaluation of Health Technology Assessment (HTA) Process from July 2018 until January 2021.
}

Georgia Kourlaba

ECONCARE LP

Alexandra Beletsi ( $\square$ alexandra.beletsi@servier.com )

Servier Hellas Pharmaceuticals EPE

\section{Research Article}

Keywords: HTA implementation, Greece, reimbursement, patient access.

Posted Date: July 1st, 2021

DOI: https://doi.org/10.21203/rs.3.rs-641812/v1

License: (a) (1) This work is licensed under a Creative Commons Attribution 4.0 International License. Read Full License 


\section{Abstract}

Background:To present the outcome of the Health Technology Assessment (HTA) process in Greece from its onset back in July 2018 till January 2021 and to quantify the median time from marketing authorization (MA) to listing especially for new medicines.

Methods: All products included in the reimbursement positive list from July 2018 to January 2021, were identified through the relevant Ministerial Decisions (MDs) posted on the website of the Ministry of Health $(\mathrm{MoH})$ and the Positive Reimbursement Lists issued this period. The following information were collected for these medicines: date that MDs and Positive Reimbursement lists were issued, the legal basis of the initial MA, the MA date, the date of price registration, and the type of the HTA application. The time from MA to listing was calculated.

Results: During the study period, 38 MDs were issued from which 35 (92\%) were positive and resulted in the inclusion of 318 medicines and $3(8 \%)$ were negatives that excluded 6 medicines. Focusing on new medicines, the median time from MA to listing was found to be 30 months with an interquartile range of 22 to 39 months. This time was statistically significantly shortened for FDC [19.3 (13-35) months], compared to biosimilars [26 (22-35) months, $p=0.09$ ] and on patent [38.5 (29-44) months, $p=0.008$ ]. For new generics, the corresponding median time was 22 (IQR: 12.5-31) months, statistically significantly lower than that of new medicines $(\mathrm{p}=0.028)$. Focusing on the four most common therapeutics areas, the median (IQR) time from MA to listing for new medicines was 28.3 (24.9-32.9) months and 34.9 (21.941.1) months, for oncologic and immunosuppressants ( $p=0.136)$, respectively, while on the field of cardiovascular and CNS there was no reimbursement of new active substances during the study period.

Conclusions: This study showed that it takes a long time for Greek patients to get access to newly registered medicines. Given that the delay in access might result in potential loss of many life years, actions should be taken by policy makers to speed up patients access to new and innovative medicines.

\section{Background}

Although, the granting of marketing authorization (MA) denotes that the benefit/risk balance for a medicine is deemed favorable, this is not enough to ensure patient access to new prescription medicines, particularly costly ones. To do this, medicines should be covered by the publicly funded health care system. However, payers worldwide are dealing with difficult decisions when allocating the limited healthcare resources across health technologies, especially after the economic crisis in 2008. As such, Health Technology Assessment (HTA) is deemed a cornerstone for decision making in health care policy, which can support the efficient use of resources. The key purpose of HTA is to achieve greater value for the money spent evaluating efficacy, safety and economic data in a systematic, transparent, unbiased and robust manner [1].

Over the past 30 years, specific bodies or programs have been established in several European countries for the implementation of HTA[2]. In Greece, the legislative framework regarding the reimbursement of 
prescribed medicines has been, recently, updated introducing an "HTA Committee" along with a "Negotiation Committee" (Law 4512/2018 and Ministerial Decision 52029/2018)[3-6]. The establishment of HTA in Greece was legislated in 2018 with the creation of the HTA committee and by setting the rules of HTA process. The HTA assessment is initiated only if the applicant submits the proofs that the medicine or new indication is already reimbursed in 5 of the following 11 countries Austria, Belgium, France, Germany, Denmark, Spain, Netherlands, Italy, Sweden, Finland and Portugal. These countries have already a well-established HTA process and this external criterion is required mainly for the new active substances of on patent medicines. ("Positive List")[3]. The main task of the HTA Committee is to assess medicines with MA in terms of clinical effectiveness focusing on added therapeutic value, quality of clinical evidence and innovation level. In parallel it was announced the creation of a Negotiation Committee with a complementary role in the HTA procedure. The main task of Negotiation Committee is to negotiate prices of medicines that have received a positive recommendation by the HTA Committee and inform back the HTA Committee about the agreement entered with manufacturers (if any). Then, the HTA Committee makes a final recommendation to the Minister of Health -the ultimate decision maker- on the inclusion or removal from the reimbursement list. To start the HTA process, Marketing Authorizations Holders (MAHs) should submit the HTA dossier to the national HTA body or committee of the countries in which they intend to market their medicines. The overall time frame within which pricing and reimbursement procedures should be completed is set by the European Commission and legislation (Transparency Directive) to 180 days for innovative products and 90 days for generic products[7]. However, given that pricing and reimbursement is a national process, with the requirements to vary across the European countries, the time from MA to reimbursement might vary across European countries, as well. For example, there is evidence demonstrating that for medicines approved between 2015 and 2018, the median time from European Union (EU)-wide MA to patient access ranged from 53 days in Germany to 877 days in Lithuania[8].

Few studies focus specifically on time to entry of new medicines in Europe and its determinants and these studies mainly focus on oncology medicines $[9,10]$ since cancer is a major contributor to the global burden of disease. To the best of our knowledge, in Greece, a country where the HTA process was lately introduced, such data is completely lacking. However, a better understanding of the time required for new medicines to enter markets and factors that might impact this time might provide useful insights for taking actions required to improve access, especially in a country like Greece, in which there is limited experience with HTA process.

In this context, the primary objective of this study was to present the outcome of the Health Technology Assessment (HTA) process in Greece from its onset back in July 2018 till January 2021. The secondary objective was to quantify the median time from marketing authorization (MA) to listing especially for new medicines listed during the study period.

\section{Methods}


All products included in the reimbursement positive list from July 2018 - when the members of the HTA committee were appointed- to January 2021, were identified through the relevant Ministerial Decisions (MDs) posted on the website of the Ministry of Health $(\mathrm{MoH})$ and the Positive Reimbursement Lists that have been issued from July 2018 until January 2021.

For the medicines included in these MDs the following information were collected:

- The date that MDs and Positive Reimbursement lists were issued.

- The date of HTA outcome as reported in the relevant MD.

- The legal basis of the initial MA (i.e. 8 (3) for originators, on patent and off patent, 10 (1) for generics, 10 (3) for hybrids, 10 (4) for biosimilars, 10 (a) well - established and 10 (b) fixed dose combinations) as reported in the price bulletin.

- The MA date as extracted from the European Medicines Agency or National Organization of Medicines websites for Centralized Procedures or Decentralized/ Mutual/ National Procedures, respectively. For the cases that the HTA application concerned a new pack size or a new strength the date of the initial MA was used since the information in the National Organization of Medicines website was limited

- The date of their registration of price as extracted from the relevant Price Bulletins issued from the $\mathrm{MoH}$. In the case of a new indication, and because the product has already been priced, due to the previous indication for which it is already on the market, the date of pricing was set the same as that of MA (assumption).

- The type of the HTA application, where the following seven categories were identified: New Medicine, New Generic, New Indication, New Pack Size, New Strength, New Pharmaceutical Form

- Moreover, all the medicines were grouped according to their ATC categorization in different therapeutic categories with the majority to be in th fields of oncology, immunosuppressants, cardiovascular and CNS.

\section{Time incurred to listing}

The time from MA to listing was calculated as the difference between the date of MA and the date that the relevant reimbursement list was issued. This total time was divided into the following time intervals: a) time from MA to pricing, b) time from pricing to the publication of MD, d) time from MD to listing, that is the actual implementation of reimbursement ensuring patients access to medicines. Moreover, the time from pricing to listing was estimated.

\section{Statistical analysis}

Categorical parameters summarized by absolute and relative frequencies $(\mathrm{N}, \%)$. Time intervals were summarized as mean, median, range (min-max) and interquartile range (25th and 75th percentile). To examine the association between some factors (i.e. the type of HTA application, the legal basis, the therapeutic area) and the time of MA to listing or its components, Student's t-test or Mann Whitney was 
used in case that the factor consisted of 2 categories and ANOVA or Kruskal-Wallis in case that the factor consisted of 3 or more categories. All tests were two-sided and carried out with a $5 \%$ a-error rate without correction for multiplicity. All statistical analyses were performed using STATA software (version 14.2, 2017, STATA Corp).

\section{Results}

During the study period, $38 \mathrm{MDs}$ were issued from which 35 (92\%) were positive and resulted in the inclusion of 318 medicines and $3(8 \%)$ were negatives that excluded 6 medicines, two of which due to a non-consensus in the negotiation phase of the procedure. The first MD was issued in July 2019 and included only 22 medicines, with most of them being generics. Figure 1 presents the number of medicines categorized by legal basis included in the positive lists issued each year.

Table 1 presents in detail the distribution of these medicines based on the legal basis of MA, the type of HTA application, the way of granting the MA and the therapeutic area. With respect to the type of HTA application, it was found that almost $18 \%$ of the listed medicines were new medicines and almost half of them (49.0\%) were new generics. As for the therapeutic area, $22.3 \%$ of the listed medicines were for cardiovascular system, followed by those for oncology (17.3\%), CNS (9.75\%) and immunosuppressants (7.55\%) (Table 1). 
Table 1

Characteristics of medicines reimbursed during the period July 2018-January 2021 in Greece $(\mathrm{N}=318)$

$N(\%)$

\section{Procedure}

Centralized

$93(29.34 \%)$

$\mathrm{DCP} / \mathrm{MRP}$

$162(51.1 \%)$

National

$62(19.56 \%)$

\section{Legal basis}

biosimilar

$26(8.18 \%)$

FDC

$14(4.40 \%)$

Generic

188 (59.12\%)

Hybrid

$10(3.14 \%)$

Off patent

$18(5.66 \%)$

On patent

$56(17.61 \%)$

Well established

$6(1.89 \%)$

\section{Application}

New strength

$16(5.03 \%)$

New generic

$156(49.06 \%)$

New indication

$11(3.46 \%)$

New medicine

$57(17.92 \%)$

New pack-size

$62(19.50 \%)$

New pharmaceutical form

5 (1.57\%)

other

$11(3.45 \%)$

\section{Therapeutic_area}

Antimycotics

$11(3.46 \%)$

Antinfectives

$11(3.46 \%)$

Blood \& blood forming

$12(3.77 \%)$

CNS

31 (9.75\%)

DCP/ MRP: Decentralized Procedure/ Mutual Recognition Procedure; FDC: Fixed Dose Combination; CVD: cardiovascular disease; CNS: Central Nervous System 


\begin{tabular}{|ll|}
\hline & N (\%) \\
\hline CVD & $71(22.23 \%)$ \\
\hline Hormones & $15(4.72 \%)$ \\
\hline Immunosuppressants & $24(7.55 \%)$ \\
\hline Oncology & $55(17.30 \%)$ \\
\hline Respiratory & $18(5.66 \%)$ \\
\hline other & $70(22.01 \%)$ \\
\hline $\begin{array}{l}\text { DCP/ MRP: Decentralized Procedure/ Mutual Recognition Procedure; FDC: Fixed Dose Combination; } \\
\text { CVD: cardiovascular disease; CNS: Central Nervous System }\end{array}$ \\
\hline
\end{tabular}

\section{Time from MA to listing}

Focusing on new medicines, the median time from MA to listing was found to be 30 months with an interquartile range of 22 to 39 months. When we further looked at the legal basis of the new medicines, we found that the median (IQR) time from MA to listing was statistically significantly shortened for FDC [19.3 (13-35) months], compared to biosimilars [26 (22-35) months, $p=0.09$ ] and on patent [38.5 (2944) months, $p=0.008]$. For new generics, the corresponding median time was 22 (IQR: 12.5-31) months, statistically significantly lower compared to that of new medicines $(p=0.028)$ (Fig. 2a).

Breaking down the overall time from MA to listing for new medicines, we found that the median (IQR) time from MA to price, from price to MD and from MD to listing was: 13.3 (6.4-14.2), 17.7 (10-25.7), and $0.3(0.3-2.2)$ months, respectively. The median (IQR) time from price to MD was statistically significantly longer in on patent [23.8 (19.5-29.4) months] compared to biosimilars [14.0 (7.5-19.4) months, $p<$ $0.001]$ and FDCs [12.9 (6.8-17.4) months, $p<0.001]$ (Fig. 2b), while no significant differences were detected into the time from MA to price (Fig. 2c) and MD to listing (Fig. 2d) among these three categories based on legal basis of new medicines.

\section{Time form MA to listing for specific therapeutic areas}

Focusing on the four most common therapeutics areas, the median (IQR) time from MA to listing for new medicines was 28.3 (24.9-32.9) months and 34.9 (21.9-41.1) months, for oncologic and immunosuppressants $(p=0.136)$, respectively, while no new active substances on the field of cardiovascular and CNS were found to be reimbursed during the study period (Table 2). Looking at the time from MA to listing for on-patent and biosimilars, separately, it was found that both in oncology and immunosuppressants this time was longer in on-patent compared to biosimilars [29.2 (28.3-36.8) vs 25.9 (22.0-31.3), $p=0.05$ for oncologic medicines and 39.8 (36.6-47.4) months] vs $24.2(21.9-34.9)$ months, $p=0.099$ for immunosuppressants]. As for new generics, no significant difference was detected among the three therapeutics areas for which new generics had been reimbursed [21.9 (12.6-25.9), 23.3 (14-37.2) and 23.5 (15.4-301.) for CNS, CVD and oncology, respectively, $p>0.05]$. 
Table 2

Time from marketing authorization to listing by therapeutic area for new generics and new medicines reimbursed between July 2018-January 2021, in Greece

\begin{tabular}{|c|c|c|c|c|}
\hline & New medicine & on patent & biosimilars & New generic \\
\hline Oncology & $\begin{array}{l}\text { Median (25th - } \\
\text { 75th) }\end{array}$ & $\begin{array}{l}\text { Median (25th - } \\
\text { 75th) }\end{array}$ & $\begin{array}{l}\text { Median (25th - } \\
\text { 75th) }\end{array}$ & $\begin{array}{l}\text { Median (25th - } \\
\text { 75th) }\end{array}$ \\
\hline $\begin{array}{l}\text { Time from MA to } \\
\text { pricing }\end{array}$ & $8.5(6.0-15.5)$ & $6.1(6.0-8.7)$ & $11.0(7.1-15.9)$ & $7.3(6.4-13.2)$ \\
\hline $\begin{array}{l}\text { Time from price to } \\
M D\end{array}$ & $19.4(10.0-23.9)$ & $\begin{array}{l}22.0(19.5- \\
28.2)\end{array}$ & $15.5(5.4-20.7)$ & $8.1(3.3-15.4)$ \\
\hline Time from MD to list & $0.3(0.3-2.2)$ & $0.3(0.3-1.9)$ & $0.6(0.1-2.2)$ & $1.0(0.3-2.8)$ \\
\hline Time from MA to list & $\begin{array}{l}28.3(24.9- \\
32.9)\end{array}$ & $\begin{array}{l}29.2(28.3- \\
36.8)\end{array}$ & $25.9(22.0-31.3)$ & $23.5(15.4-30.1)$ \\
\hline $\begin{array}{l}\text { Time from price to } \\
\text { listing }\end{array}$ & $\begin{array}{l}21.9(10.3- \\
26.2)\end{array}$ & $\begin{array}{l}22.3(22.3- \\
28.5)\end{array}$ & $16.7(7.2-23.7)$ & $10.3(3.9-15.5)$ \\
\hline \multicolumn{5}{|l|}{ Immunosuppresants } \\
\hline $\begin{array}{l}\text { Time from MA to } \\
\text { pricing }\end{array}$ & $10.8(6.9-18.8)$ & $13.5(7.2-17.1)$ & $10.0(6.4-18.8)$ & \\
\hline $\begin{array}{l}\text { Time from price to } \\
M D\end{array}$ & $15.5(12.0-26.4)$ & $\begin{array}{l}26.2(19.5- \\
31.5)\end{array}$ & $13.4(12.0-15.4)$ & \\
\hline Time from MD to list & $2.2(0.1-2.5)$ & $2.5(2.2-2.8)$ & $2.2(0.1-2.2)$ & \\
\hline Time from MA to list & $\begin{array}{l}34.9(21.9- \\
41.1)\end{array}$ & $\begin{array}{l}39.8(36.6- \\
47.7)\end{array}$ & $24.2(21.9-34.9)$ & \\
\hline $\begin{array}{l}\text { Time from price to } \\
\text { listing }\end{array}$ & $\begin{array}{l}25.5(14.2- \\
27.3)\end{array}$ & $\begin{array}{l}28.5(22.3- \\
34.0)\end{array}$ & $15.5(14.2-15.5)$ & \\
\hline \multicolumn{5}{|l|}{ CVD } \\
\hline $\begin{array}{l}\text { Time from MA to } \\
\text { pricing }\end{array}$ & & & & $8.3(5.9-13.9)$ \\
\hline $\begin{array}{l}\text { Time from price to } \\
M D\end{array}$ & & & & $7.5(3.5-17.0)$ \\
\hline Time from MD to list & & & & $0.5(0.3-2.8)$ \\
\hline Time from MA to list & & & & $23.3(14-37.2)$ \\
\hline $\begin{array}{l}\text { Time from price to } \\
\text { listing }\end{array}$ & & & & $10.3(6.3-19.1)$ \\
\hline \multicolumn{5}{|l|}{ CNS } \\
\hline $\begin{array}{l}\text { MA:Marketing Authori } \\
\text { Nervous System }\end{array}$ & tion; MD: minis & decision; CVD & ovascular disea & NNS: Central \\
\hline
\end{tabular}




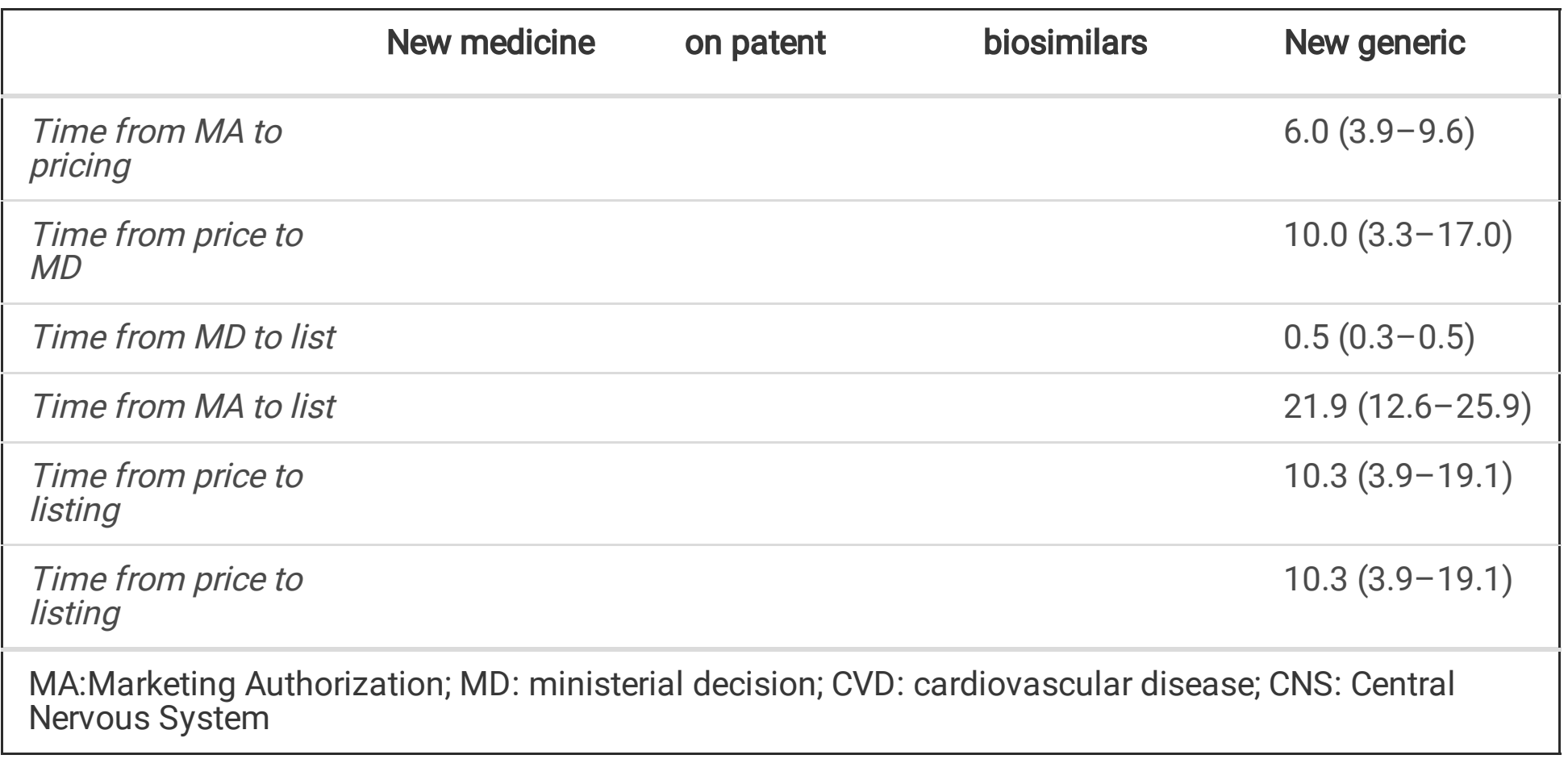

The median (IQR) time from price to MD for new medicines, did not found to differ significantly between oncology and immunosuppressants [19.4 (10-23.9) and 15.4 (12.0-26.4) months, respectively, $p=0.669$ ], while in both therapeutic areas, this time was significantly prolonged for on patent compared to biosimilars $(p=0.022)$. With respect to new generics, the median time from price to MD ranged from 7.5 months in CVD to 10 months in CNS (Table 2).

Finally, for immunosuppressants, the median time between MD to listing exceed the 2 months for new medicines as opposite to oncologic medicines that was 8 days (Table 2).

\section{Time form MA to listing for selected on patent medicines}

Figure 3 presents the time form MA to listing as well as its components for the 8 on patent new medicines in oncology. It seems that the time from MA to listing ranges from 860 (Durvalumab)) days to 1228 (Avelumab), with the time from price to MD to range from 306 (Axicabtagene Ciloleucel) to 1005 (Atezolizumab) days. The time from MA to pricing seems to be at least 6 months, with Axicabtagene Ciloleucel and Avelumab experiencing the longer such time (575 and 322 days, respectively). Moreover, it seems that for 2 medicines (Encorafenib and Binimetinib), almost 3 months passed from the date that the MD issued till the date that the positive list was updated including these products.

Figure 4 presents the time form MA to listing as well as its components for the 6 on patent immunosuppressants. It seems that the time from MA to listing ranges from 643 (Risankizumab) days to 1739 (Ixecizumab), with the time from price to MD to range from 306 (Risankizumab) to 1134 (Ixecizumab) days. The time from MA to pricing seems to be at least 7 months. Moreover, it seems that for almost all products except for Risankizumab, almost 2.5-3 months passed from the date that the MD issued till the date that the positive list was updated including these products. 


\section{Discussion}

During the massive changes that were implemented in Greece in the health system during the period of 2010-2020 the requirement of the creation of HTA body was always a prerequisite. The law for the establishment of an HTA committee was voted in January 2018 [4] were the Ministerial Decisions describing the procedures and requirements were released in July and August $2018[5,6]$. To the best of our knowledge, this is the first research work aiming to assess the efficiency of the HTA procedure in Greece after having the experience of 2.5 years of operation of the HTA committee. The outcome of the HTA process in Greece from its onset, back in July 2018, to January 2021, along with the median time from MA to listing new medicines during the study period were presented in this study.

After the establishment of the law the first MDs issued based in the new procedure were announced in July 2019 and for 22 medicines. This result was mainly driven by two reasons: a) inadequate staffing levels for the assessment and lack of assessors because of the strict rules set for the conflict of interest, b) HTA assessment of all medicines without exceptions including categories as generics, providing a huge burden in the two committees. Political changes in 2019 conclude in further delays as there was a reshuffle in the committee members.

During 2019 and 2020 there were done some legislative changes in the law to improve the productivity of the committees such the introduction of fast-track process for biosimilars and vaccines, exception of some categories from the HTA assessment and without negotiation if their price was low and subsequently, if they didn't have a negative budget impact like generics, FDC etc [11-13]. All the above legislative changes led to an acceleration of the process as rationalizes the number of files that need full HTA assessment and reduce the burden of the committee. The result of this was to have 254 medicines included in the list for 2020 followed by another 42 medicines in January 2021 from which the 59\% were Generics, $17 \%$ on patent medicines and $9 \%$ biosimilars.

Our analyses revealed that the median (IQR) time between MA to listing for new medicines (including onpatent, biosimilars and FDC) was 30 (22-39) months. For new generics, this time was estimated to be 22 (12.5-31) months, something that could be explained by the drastic legislative changes conducted during 2019 and 2020 exempting generics from the HTA process. Among the new medicines, on-patent drugs delayed significantly more to obtain access to the Greek market compared to new biosimilars, something that could be explained by the requirement of the external criterion obligation which affects mainly new active substances and innovative products and provoke further delay in the initiation of the assessment by the legislative changes, as well.

To the best of our knowledge, limited comparable data to those presented in this work are available from other European countries. A recently published study aiming to assess the access in Europe to newly registered cancer drugs, revealed that the average time between MA and first access, defined as the first sale in each country, in 28 European countries was 398 days (range 17-1187 days). In general, patients in Germany, the UK, and Austria had the most rapid potential access, with averages of 17, 22, and 31 days, respectively. Greece and many Eastern European countries were close to the upper limit [14]. In the same 
study, it is mentioned that this delay in patient access to specific cancer drugs might be related with a significant loss of life years.

The time between MA to listing is affected by both the pricing and reimbursement system followed in each country. To assess the impact of reimbursement process in Greece, the time between price publication and listing was also calculated. It was found that almost 2 years were required to get a new medicine access to the Greek market from the date of price publication. Given that the HTA process should be completed within 6 months from submission of HTA application, based on the legislation, this delay could be explained from either the delayed submission after pricing due to external criterion required or delay in HTA process. Since, data on HTA submission date were not available we cannot conclude on which of these factors is responsible for delay. Moreover, it was found that $1 / 4$ of new medicines took at least 2 months from the time the MD was issued until the final inclusion in the reimbursement list. This indicates that actions should be taken by the decision policy makers so that the products to be included automatically in the reimbursement list directly after MD.

A recent report of OECD concluded that one of the key challenges is the often-significant uncertainty surrounding the degree of clinical benefit offered by a new medicine at the time of market entry[15]. Especially in oncology, as new indications are frequently approved in earlier phases of development. This is often driven by the need to have a rapid access to promising therapies in areas of unmet medical need. The challenge of the HTA bodies is that the uncertainty of the value is higher. Recently a common approach for overcoming this obstacle is the use of managed entry agreements, mainly with the objective of managing financial risks. This key point could be addressed in Greece with the further evolution of the Negotiation Committee, setting concrete criteria for innovation and establishing a mechanism of horizon scanning to anticipate the challenges.

\section{Study Limitations}

Although this study is unique, it still suffers from several limitations and it should be viewed in that light. First of all, the date of HTA submission was not available and as such we could not estimate the length of HTA review process. Secondly, the date of positive HTA opinion or negotiation conclusion are not revealed and as such it was not feasible to estimate the length of each one of these two procedure that are crucial for the final reimbursement decision.

\section{Conclusion}

This study showed that it takes a long time for Greek patients to get access to newly registered drugs. Given that the delay in access might result in potential loss of many life years, actions should be taken by policy makers to speed up the access to new and innovative medicines. Although it is not clear how the external criterion affects the delay in Greek patients' access, policy makers could examine if not the abolition of this criterion, at least its non-mandatory character at the time of HTA submission, so that MAHs can proceed to the submission directly after getting a price. Moreover, the creation of an 
independent HTA organization with dedicated specialized personnel instead of an HTA committee with part time personnel could probably help in improving the time to patients' access. In addition, partnership and dialogue among the relevant stakeholder's government, industry and patients, could promote mutual agreements in order to ensure the equity and sustainability of health care system.

\section{Abbreviations}

HTA

Health Technology Assessment; MA:Marketing Authorization; MAH:Marketing Authorization Holder; MD:Ministerial Decision; FDC:Fixed Dose Combinations; IQR:Interquartile Range; MoH:Ministry of Health; OECD:Organisation for Economic Co-operation and Development; CNS:Central Nervous System; CVD:Cardiovascular Diseases.

\section{Declarations}

Ethics approval and consent to participate

N/A

\section{Consent for publication}

N/A.

\section{Availability of data and materials}

The datasets used and/or analyzed during the current study are available from the corresponding author on reasonable request.

\section{Competing interests}

The authors declare that no competing interests exist.

\section{Funding}

Servier Hellas Pharmaceuticals EPE funded the publication fee of this project. The content is solely the responsibility of the authors and does not necessarily represent the official views of Servier Hellas.

\section{Author Contribution}

GK and A.B. contribute to the concept and design of the project. AB was responsible for the collection of the data and GK for the statistical analysis. $A B$ and GK contributed to the interpretation of the data and drafted the manuscript. Both authors have reviewed the final manuscript. Both authors read and approved the final manuscript. 


\section{Acknowledgement}

The authors would like to thank Servier Hellas Pharmaceuticals EPE

\section{References}

1. Banta D., What is technology assessment? Int J Technol Assess Health Care 2009. 25: p. 7-9.

2. Sorenson, C. and K. Chalkidou, Reflections on the evolution of health technology assessment in Europe. Health Econ Policy Law, 2012. 7(1): p. 25-45.

3. Kanavos, P., et al., Implementing health technology assessment (HTA) in Greece: Myths, reality and cautionary tales. ARCHIVES OF HELLENIC MEDICINE, 2019. 36(4).

4. GOVERNMENT GAZETTE OF THE HELLENIC REPUBLIC. Law 4512/2018. Arrangements for the implementation of the structural reforms of the economic adjustment programmes and other provisions. FEK 5/A/17.1.2018.

5. GOVERNMENT GAZETTE OF THE HELLENIC REPUBLIC. Ministerial Decision no 52029/2018. FEK 2768/B/11.7.2018.

6. GOVERNMENT GAZETTE OF THE HELLENIC REPUBLIC. Ministerial Decision no 63025/2018. FEK 3585/B/23.8.2018.

7. The Council of the European Communities., Council Directive of 21 December 1988. Off J Eur Union 1988: NoL40/8.

8. European Federation of Pharmaceutical Industries., Patients W.A.I.T. Indicator 2019 Report. Brussels: European Federation of Pharmaceutical Industries, 2019. 2020.

9. Ferrario, A., Time to Entry for New Cancer Medicines: From European Union-Wide Marketing Authorization to Patient Access in Belgium, Estonia, Scotland, and Sweden. Value Health, 2018. 21(7): p. 809-821.

10. Maraiki, F., et al., International HTA Experience with Targeted Therapy Approvals for Lung Cancer. Pharmacoecon Open, 2019. 3(1): p. 103-117.

11. GOVERNMENT GAZETTE OF THE HELLENIC REPUBLIC Law 4633/2019. Establishment of a National Public Health Organization (EODY), regulations for tobacco products, others issues of the Ministry of Health and other classes. FEK /A/16.10.2019.

12. GOVERNMENT GAZETTE OF THE HELLENIC REPUBLIC Law 4683/2020. Ratification from 20.3.2020 P.N.P. "Urgent measures to address its consequences risk of spread of COVID-19 coronavirus, support for society and business and ensuring smooth operation market and public administration "(AD 68) and other provisions. FEK /A/10.04.2020.

13. GOVERNMENT GAZETTE OF THE HELLENIC REPUBLIC Law 4690/2020. Ratification: a) of from 13.4.2020 P.N.P. "Measures for addressing the ongoing consequences of the coronavirus pandemic COVID-19 and other all urgent provisions "(AD 84) and b) of from 1.5.2020 P.N.P. "Further measures 
for addressing its ongoing consequences of the COVID-19 coronavirus pandemic and the social and economic normalization (AD 90) and other provisions. FEK /A/30.05.2020.

14. Uyl-de Groot, C.A., et al., Unequal Access to Newly Registered Cancer Drugs Leads to Potential Loss of Life-Years in Europe. Cancers (Basel), 2020. 12(8).

15. Organisation for Economic Co-operation and Development., Addressing challenges in access to oncology medicines. 2020.

\section{Figures}



\section{Figure 1}

Number of medicines categorized by legal basis included in the positive lists issued each year. FDC: Fixed Dose Combination 

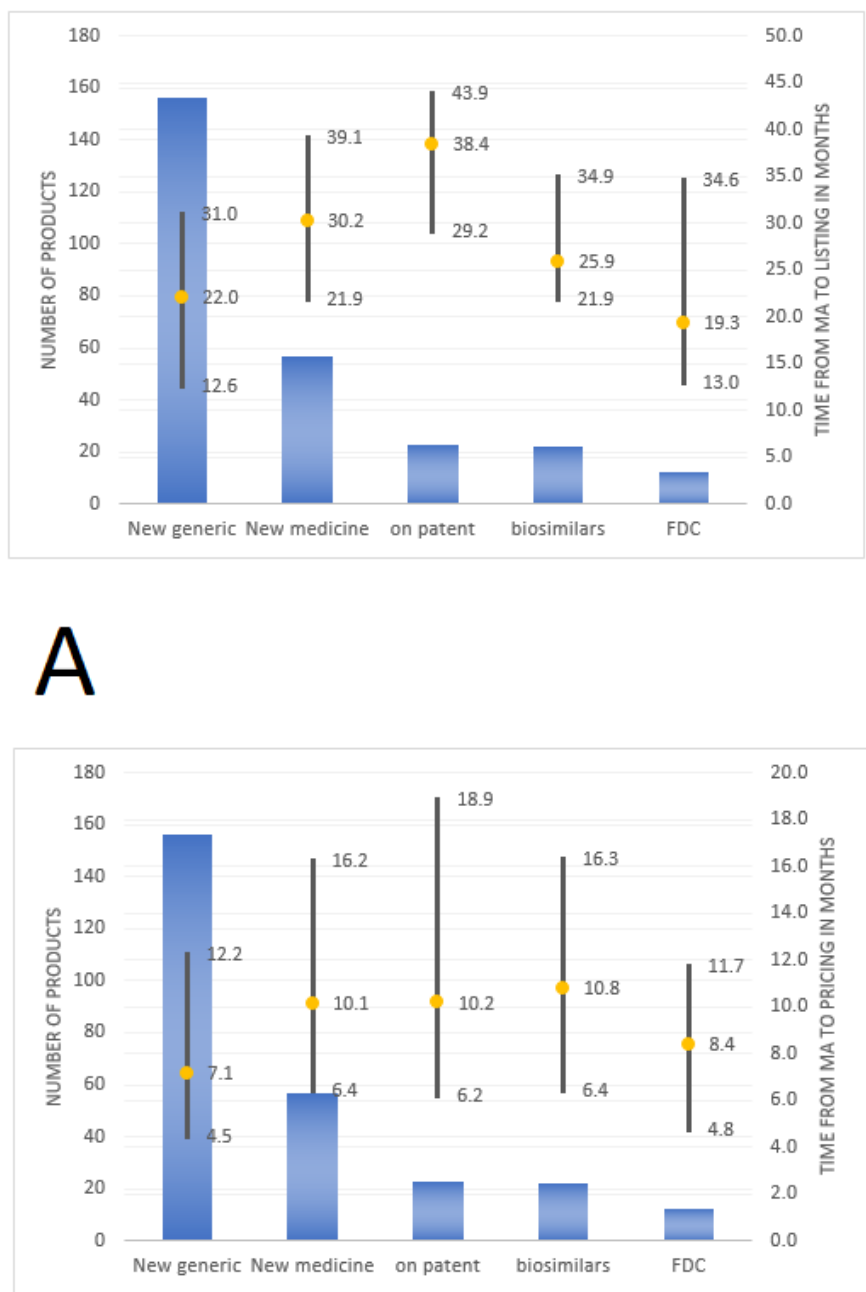

$\mathrm{C}$

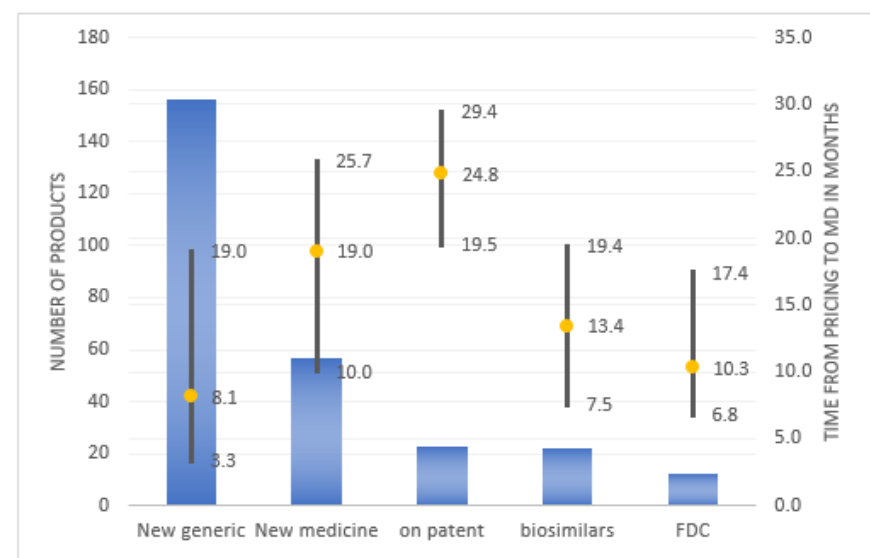

B

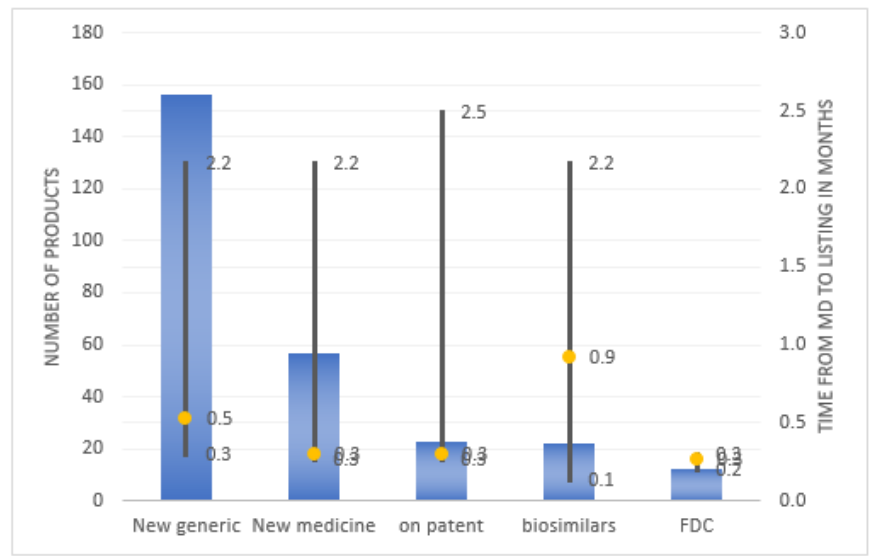

D

\section{Figure 2}

a: Time from marketing authorization (MA) to listing for new generics and new medicines reimbursed between July 2018-January 2021, in Greece. FDC: Fixed Dose Combination Blue bars represent the number of products belonging in each category; the low and upper limits of the solid line represent the 25th and 75th percentile of time and the yellow cycle represents the median time. b: Time from pricing to MD for new generics and new medicines, reimbursed between July 2018-January 2021, in Greece. c: Time from marketing authorization (MA) to pricing for new generics and new medicines, reimbursed between July 2018-January 2021, in Greece d: Time from MD to listing for new generics and new medicines, reimbursed between July 2018-January 2021, in Greece. MD: Ministerial Decision; FDC: Fixed Dose Combination Blue bars represent the number of products belonging in each category; the low and upper limits of the solid line represent the 25 th and 75 th percentile of time and the yellow cycle represents the median time 


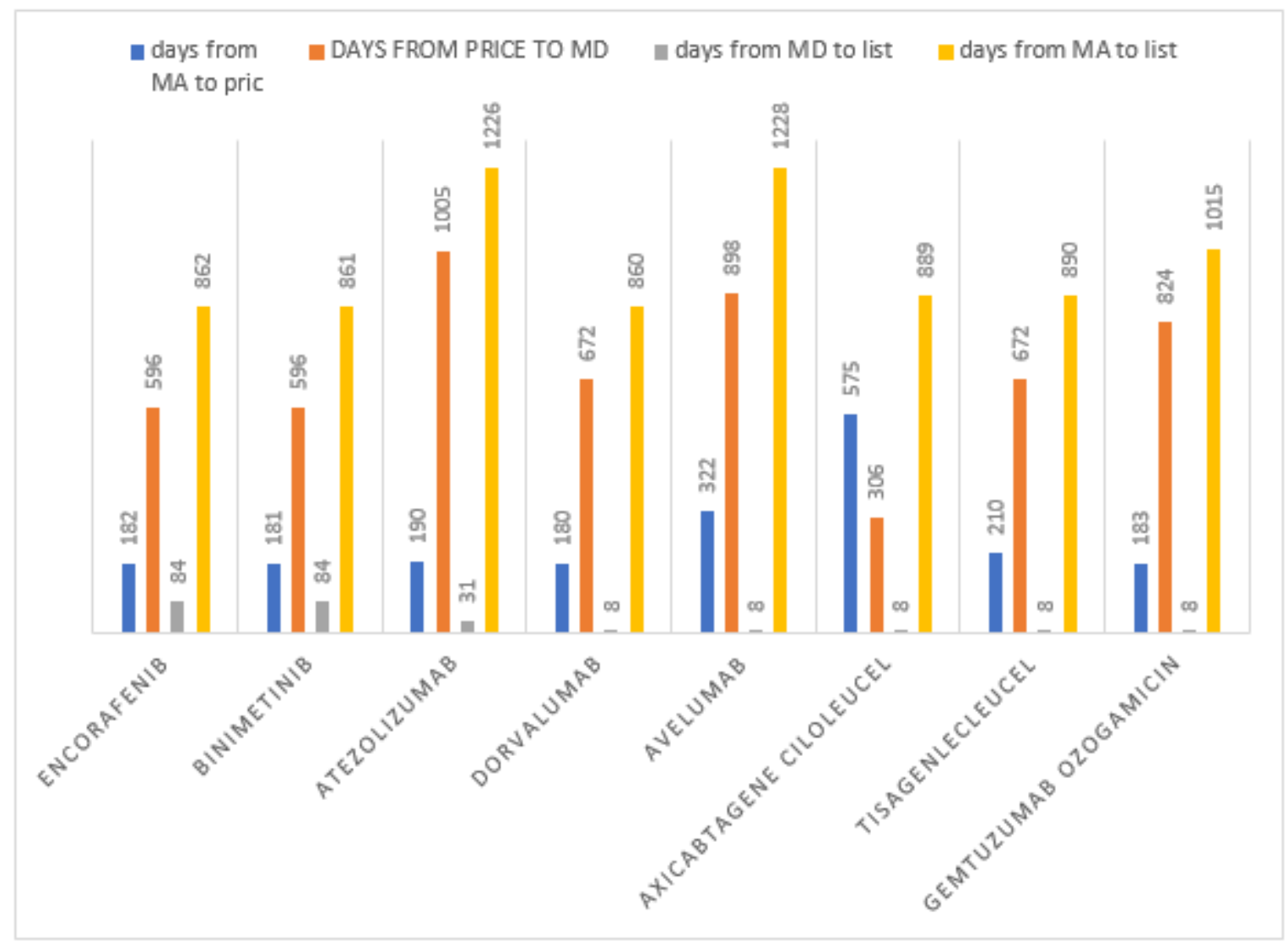

\section{Figure 3}

Time from marketing authorization to listing and its components for the 9 oncologic products reimbursed during the study period in Greece. MD: Ministerial Decision; MA: Marketing Authorization

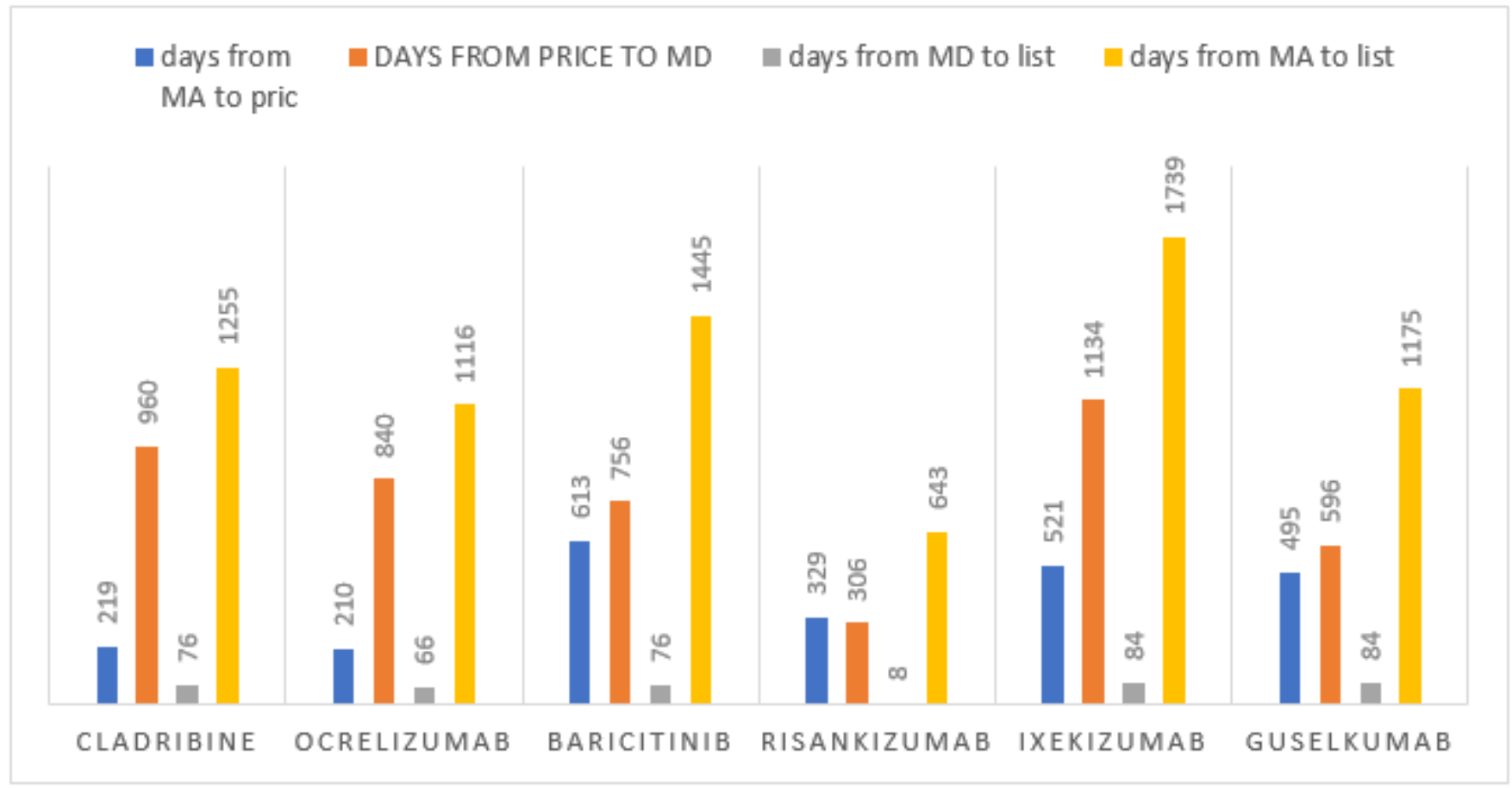

Figure 4 
Time from marketing authorization to listing and its components for the 6 immunosuppressants reimbursed during the study period in Greece. MD: Ministerial Decision; MA: Marketing Authorization 